\title{
Clinical judgement of airway inflammation versus sputum cell counts in patients with asthma
}

\author{
K. Parameswaran, E. Pizzichini, M.M. Pizzichini, P. Hussack, A. Efthimiadis, F.E. Hargreave
}

Clinical judgement of airway inflammation versus sputum cell counts in patients with asthma. K. Parameswaran, E. Pizzichini, M.M. Pizzichini, P. Hussack, A. Efthimiadis, F.E. Hargreave. (C) ERS Journals Ltd 2000.

ABSTRACT: The inflammatory component of asthma is usually assessed indirectly by symptoms and spirometry, these may be inaccurate. It can now be assessed directly and reliably by the examination of sputum cell counts. There is no information on how clinical assessment of the presence and type of airway inflammation compares with actual measurements.

In this single-centre observational study, sputum was collected from 76 consecutive adults with asthma attending a tertiary chest clinic after their physicians had recorded the expected cell counts in sputum. The authors examined the extent of agreement between clinical judgement of sputum cell counts and actual counts in asthmatic patients (Cohen's Kappa) and the possible predictors of agreement (multiple logistic regression).

Sixty-seven of the 76 sputum samples were suitable for analysis. Agreement between expected and actual cell counts occurred in 30/67 patients. The overall agreement for the different cell types was poor (estimated $\kappa=0.14,95 \%$ confidence interval $(\mathrm{CI})=0.02,0.26)$. The experience of the physician in using sputum cell counts in clinical practice, steroid requirement at the time of assessment, and control of asthma as assessed by the physician or by the patient could not predict the chances of agreement or disagreement. Unaware of the sputum results, the physicians often changed treatment in a way that seemed inappropriate for the cell counts present.

There is poor agreement between clinical judgement of the presence and type of airway inflammation in asthmatic patients and sputum cell counts. The impact of sputum examination on the outcomes of anti-inflammatory treatment now needs investigation.

Eur Respir J 2000; 15: 486-490.
Asthma Research Group, Dept of Medi-
cine, St. Joseph's Hospital and McMaster University, Hamilton, Ontario, Canada.

Correspondence: F.E. Hargreave

Firestone Regional Chest and Allergy Unit St. Joseph's Hospital

50 Charlton Avenue East

Hamilton, Ontario

Canada L8N 4A6

Fax: 9055216158

Keywords: Asthma

clinical judgement

inflammation

sputum cell counts

Received: June 211999

Accepted after revision November 291999
Airway inflammation is considered to be the cause of the symptoms and physiological abnormalities of asthma and guidelines suggest that it should be the primary target of treatment $[1,2]$. The inflammation is characteristically eosinophilic [3] and responds to corticosteroid treatment $[4,5]$. However, the symptoms of asthma are not specific, many patients appreciate variable airflow limitation poorly [6] and these features do not necessarily correlate with airway eosinophilia [7]. Furthermore, there are other types of inflammation, particularly neutrophilic, caused by bacterial [8] and viral infections [9] or pollutants [10], which may not respond to treatment with corticosteroids. It is therefore not unreasonable to consider that the indirect clinical assessment of airway inflammation may often be inaccurate.

The introduction of induced sputum as a direct and reliable method to measure indices of airway inflammation noninvasively makes it possible now to examine this issue [11-13]. Although sputum examination has not been established as the "gold standard" for sampling airway secretions, it provides cell counts qualitatively similar to those obtained by analysis of bronchial wash [14, 15], lavage [14-18] and biopsy [16, 17]. The authors considered that if the clinical assessment of the presence and type of airway inflammation compared well with the sputum cell counts, then this additional test may not be useful in practice. However, if it did not, further studies to investigate how the test influences the effects of treatment will be indicated. The authors therefore compared the extent of agreement between clinical judgement of sputum cell counts and actual counts in asthmatic patients. Possible predictors of agreement were also examined and the cell counts were compared with the changes in treatment that the physicians intended to make without knowing the counts. The study was not intended to examine the agreement between clinical judgement of asthma control or asthma diagnosis with sputum cell counts, or to prospectively evaluate asthma treatment outcomes based on sputum cell counts.

\section{Methods}

\section{Subjects}

Seventy-six consecutive adult asthmatic patients attending the outpatient clinics of six respiratory physicians at the Firestone Regional Chest and Allergy Unit were enrolled in the study (tables 1 and 2). The clinic sees patients with a 
Table 1. - Subjects' characteristics

\begin{tabular}{lccc}
\hline & Normal & Eo & $\mathrm{N}$ \\
\hline $\mathrm{n}$ & 40 & 19 & 8 \\
Age yrs & $48 \pm 15$ & $49 \pm 13$ & $42 \pm 17$ \\
Male n & 21 & 9 & 4 \\
Atopic* n & 31 & 16 & 7 \\
Smoking: current/ex n & $4 / 16$ & $3 / 7$ & $1 / 4$ \\
Duration of asthma yrs & $17 \pm 14$ & $15 \pm 11$ & $13 \pm 11$ \\
FEV1 L & $2.5 \pm 0.7$ & $2.5 \pm 0.8$ & $2.7 \pm 1.1$ \\
FEV1 \% predicted & $80.5 \pm 18.0$ & $78.0 \pm 15.0$ & $79.0 \pm 19.5$ \\
FEV1/VC \% & $70.4 \pm 13.4$ & $67.1 \pm 9.4$ & $72.3 \pm 14.2$ \\
PC20 methacholine** & $2.0 \pm 6.2$ & $1.2 \pm 5.5$ & $1.1 \pm 7.4$ \\
mg.mL $\mathrm{mL}^{-1}$ & & & \\
\hline
\end{tabular}

Values are expressed as mean \pm SD or absolute numbers. *: Atopic means one or more positive early responses in allergy skin-prick tests; **: geometric mean, geometric SD. Eo: eosinophil; N: neutrophil; FEV1: forced expiratory volume in one second; VC: vital capacity; $\mathrm{PC} 20$ : provocative concentration causing a $20 \%$ fall in FEV1.

range of severity of asthma. Sixty-five of them were referred by three physicians who had been using sputum cell counts routinely in the clinic. The physician's diagnosis of asthma was accepted if the patients had symptoms of episodic wheeze, chest tightness and dyspnoea and one or more of the following criteria: 1) bronchodilator reversible airflow limitation indicated by forced expiratory volume in one second (FEV1) \% predicted or FEV $1 \%$ was $<70 \%$, which increased by $15 \%$ from baseline after $200 \mu \mathrm{g}$ salbutamol; 2) methacholine airway hyperresponsiveness (provocative concentration causing a $20 \%$ fall in FEV $1\left(\mathrm{PC}_{20}\right)<8 \mathrm{mg} \cdot \mathrm{mL}^{-1}$ ) if the FEV $1 \%$ predicted or $\mathrm{FEV} 1 \%$ was $\geq 70 \%$; or 3 ) daily variability of peak expiratory flow (PEF) of $\geq 20 \%$. Patients with any known coexistent lung disease like smoker's chronic airflow limitation (best FEV $1 \%$ predicted or $\mathrm{FEV}_{1} \%<60 \%$ ), emphysema, pneumonia or bronchiectasis were not included. The study was approved by the hospital research Ethics Committee and all subjects gave written informed consent.

\section{Design}

The study was cross-sectional. The patients were enrolled at their routine clinic visits. After clinical and spirometric assessment, the physicians were requested to fill in a brief three item questionnaire regarding: 1) their over-all assessment of whether the asthma was controlled or not, based on symptoms, spirometry and any other previous investigations that the patients might have undergone; 2) what they thought the sputum cell counts would show (normal, predominant eosinophilia, significant neutrophilia, both, uncertain); and 3) any change in treatment that they proposed to make (commence or increase inhaled steroid, commence or increase prednisone, commence antibiotic, no change, other changes). Since the objective of the study was not to correlate sputum cell counts with asthma severity or asthma control, the authors did not use a validated questionnaire to document this information. It was left to the individual physicians to make a global assessment of the patient, based on symptoms, spirometry and airway responsiveness and available information on response to previous treatment and sputum macroscopic appearance, to assist the physician to make a calculated assessment of the sputum cell count. The patients were then seen by the research staff to document their clinical and demographic characteristics. The patients rated their over-all asthma symptoms as either feeling at their best or worse than their best. Spontaneous or, if this was not possible, induced sputum was collected and cell counts were made blind to the clinical details; these have been shown to give similar cell counts [19].

\section{Clinical methods}

Spirometry [20] and allergy skin-prick tests with 19 common aeroallergen extracts [21] (if not performed in the past 12 months) were performed according to standard procedures. Post-bronchodilator FEV1 was recorded. Sputum was induced by hypertonic saline according to the method described by Pizzichini et al. [11] with slight modifications. Sputum was selected from saliva, its colour was recorded and it was processed within $2 \mathrm{~h}$ as described by Pizzichini et al. [22]. Briefly, sputum was treated with $0.1 \%$ dithiothreitol (from Sputolysin 10\%; Calbiochem Corp., San Diego, CA, USA) followed by Dulbecco's phosphate-buffered saline. The suspension was filtered and nonsquamous total count and cell viability were determined. The filtrate was centrifuged, and two coded cytospins were prepared, and stained by Wright's stain. At least 400 intact nonsquamous cells were counted on one stained cytospin. Significant eosinophilia was defined as $>3 \%$ and a neutrophilia consistent with infection as $>80 \%[9,11,23]$.

\section{Analysis}

All data were analysed using the statistical package SPSS for Windows $\AA$, release 7.5 (SPSS, Chicago, IL, USA) and Stat-Exact for Windows $\AA$, release 3.0 (Cytel Software Corporation, Cambridge, MA, USA). Patient

Table 2. - Assessment of asthma control versus sputum cell counts ( $\mathrm{n}$ )

\begin{tabular}{|c|c|c|c|c|c|c|c|c|c|}
\hline \multirow{2}{*}{$\begin{array}{l}\text { Cell } \\
\text { counts }\end{array}$} & \multicolumn{2}{|c|}{ Physician assessment } & \multicolumn{2}{|c|}{ Patient assessment } & \multicolumn{3}{|c|}{ Corticosteroid requirement* } & \multicolumn{2}{|c|}{$\mathrm{FEV} 1 / \mathrm{VC}$} \\
\hline & Controlled & Uncontrolled & At best & Worse & None & $<1000 \mu \mathrm{g}$ & $>1000 \mu \mathrm{g}$ & $>60 \%$ & $<60 \%$ \\
\hline Normal & 25 & 15 & 21 & 19 & 8 & 17 & 15 & 31 & 9 \\
\hline Eo & 5 & 14 & 4 & 15 & 4 & 6 & 9 & 13 & 6 \\
\hline $\mathrm{N}$ & 3 & 5 & 3 & 5 & 2 & 4 & 2 & 5 & 3 \\
\hline Uncertain & 3 & 6 & 3 & 6 & 1 & 2 & 6 & 6 & 3 \\
\hline Total & 36 & 40 & 33 & 43 & 15 & 29 & 32 & 55 & 21 \\
\hline
\end{tabular}

*: Inhaled beclomethasone or equivalent. Eo: eosinophil; N: neutrophil (percentage differential count). The table includes the clinical details on the nine patients whose sputum samples were inadequate ("uncertain"). 
characteristics were summarized using descriptive statistics. Overall agreement between physician's assessment of sputum differential cell count and actual sputum cell counts was examined using Cohen's unweighted Kappa. Logistic regression analysis (backward elimination strategy using the likelihood-ratio test) was used to examine the relationship between agreement or disagreement (response variable) and physician's experience with sputum cell counts and severity of asthma (explanatory variables). The variables that were entered into the model were: 1) expertise of the physician (experience with sputum cell counts in practice or no experience); 2) daily steroid requirement at the time of assessment (beclomethasone $\leq 1000 \mu \mathrm{g}$ or equivalent or $>1000 \mu \mathrm{g}$ ); 3) control of asthma at the time of assessment as assessed by the physician; 4) symptom assessment by the patient; and 5) severity of airflow limitation as assessed by FEV1\% $(\geq 60 \%$ or $<60 \%)$.

\section{Results}

Sputum, suitable for analysis, was obtained from 67/76 patients (table 3 ). Of these, 40 had normal cell counts, 19 had an eosinophilia and eight had a neutrophilia which was considered to be consistent with infection (table 2). None had an increase in both cell types. The sputum was unsuitable for analysis in nine samples because of insufficient processable material in five, excessive squamous cell contamination of $>20 \%$ in two and excessive cell degeneration and low viability of $<20 \%$ in two. These nine were classified as "uncertain" for the purposes of testing for agreement.

Agreement between clinical judgements of the presence and type of airway inflammation and sputum cell counts occurred only in 30/67 (45\%) (estimated $\kappa=0.114,95 \%$ confidence interval $(\mathrm{CI})=0.02,0.26)$ (fig. 1). The $\kappa(95 \%$ CI) for normal counts was $0.25(0.05-0.45)$, for eosinophilia was $0.04(-0.16-0.24)$ and for neutrophilia was $0.04(-0.06-0.14)$.

Of the 36 patients in whom asthma was clinically judged to be controlled, five had eosinophilic and three had neutrophilic inflammation. Similarly, of the 40 patients who were clinically judged to have uncontrolled asthma, $15 \mathrm{had}$ normal sputum cell counts (table 2). In the logistic regression model, asthma control as assessed by the physicians or patients, steroid requirement at the time of assessment, severity of airflow limitation or expertise of the physician with sputum cell counts, could not predict agreement or

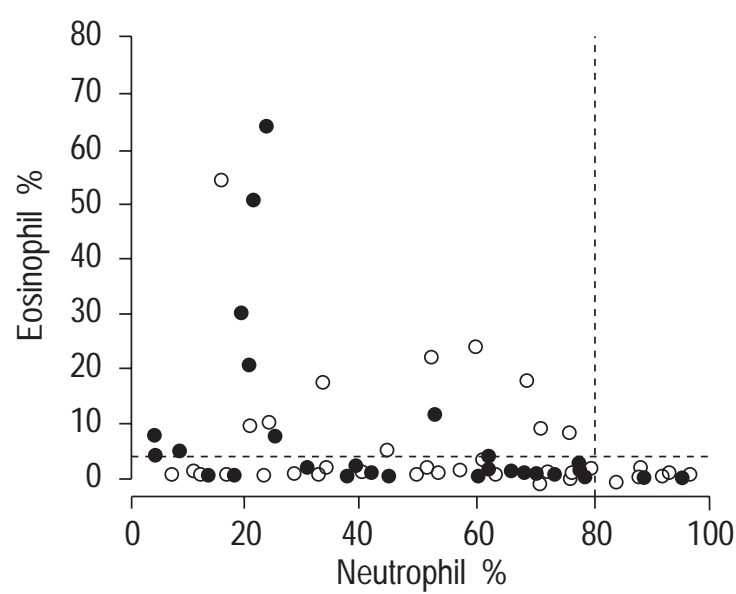

Fig. 1. - Sputum cell counts versus clinical judgement. Individual values of sputum eosinophils (per cent) are plotted against sputum neutrophils (per cent). : agreement between sputum cell counts and clinical judgement of significantly raised cell counts; $\bigcirc$ : disagreement. Horizontal dashed line is the upper limit for sputum eosinophil count (3\%). Vertical dashed line is the upper limit for sputum neutrophil count $(80 \%)$

disagreement (sensitivity $73 \%$, specificity $54 \%$, $\mathrm{p}=0.02$, Hosmer-Lemeshow Chi-square 5.19, degrees of freedom $8, \mathrm{p}=0.7)$.

The authors examined the treatment plan of the physicians when they were unaware of the sputum results (fig. 2 ). The physicians intended to commence or increase the dose of inhaled steroids or prednisone in 14 of the 40 patients with a normal sputum cell count and four of the eight patients with a significantly high neutrophil count without eosinophilia. They did not intend to commence or increase the dose of inhaled steroid or prednisone in 11 of the 19 patients with a raised eosinophil count.

\section{Discussion}

This study demonstrates that the clinical judgment of the presence and type of airway inflammation disagreed 55\% of the time with the inflammation measured by sputum cell counts. This suggests that the ability of physicians to predict the presence and type of inflammation, based on clinical assessment, is poor. As a result, the decisions on anti-inflammatory treatment can be inappropriate.

Table 3. - Sputum characteristics $(n=67)$

\begin{tabular}{|c|c|c|c|}
\hline & Normal & Eo & $\mathrm{N}$ \\
\hline \multicolumn{4}{|l|}{ Colour $n$} \\
\hline Mucoid & 39 & 15 & 2 \\
\hline Mucopurulent & 1 & 4 & 4 \\
\hline Purulent & 0 & 0 & 2 \\
\hline Viability $\%$ & $67(40-95)$ & $63(20-85)$ & $80(30-93)$ \\
\hline Total cell count $\times 10^{6}$ cells $\cdot \mathrm{mL}^{-1}$ & $3.1(0.9-11)$ & $4.0(1.1-9.7)$ & $30.1(15-47)$ \\
\hline $\mathrm{N} \%$ & $52(7-77)$ & $25(4.3-77.8)$ & $89.7(85.3-97.8)$ \\
\hline Eo $\%$ & $0.5(0-3)$ & $11.2(3.5-64.0)$ & $0.3(0-1.8)$ \\
\hline Macrophages \% & $50.4(12-92.4)$ & $36.5(12.8-88.3)$ & $9(2.2-24.4)$ \\
\hline Lymphocytes \% & $0.8(0-4)$ & $0.3(0-4.3)$ & $0.5(0-1.7)$ \\
\hline Bronchial epithelial cells \% & $0(0-7)$ & $0(0-3.3)$ & $0(0-0.3)$ \\
\hline
\end{tabular}

The sputum counts are expressed as median (range) values. Eo: eosinophil; N: neutrophil. 


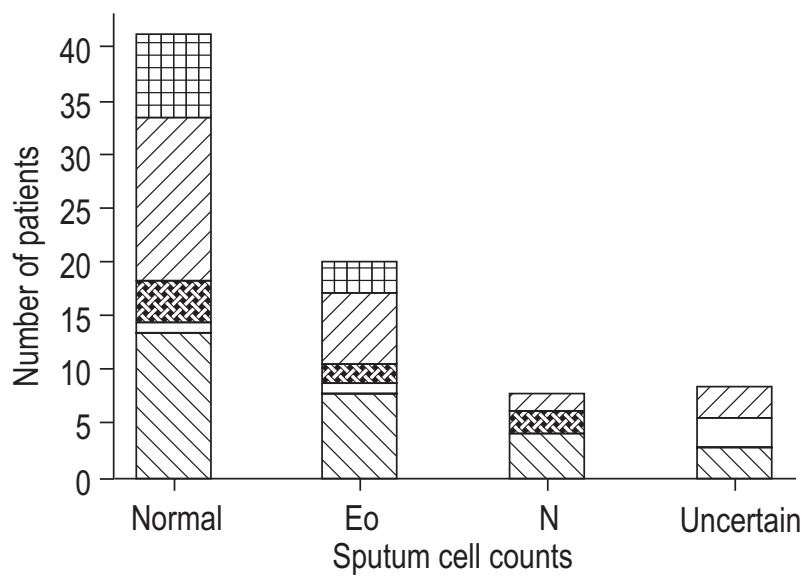

Fig. 2. - Sputum cell counts and physician's treatment plans. The cell counts (Eo: eosinophilia; N: significant neutrophilia) are plotted against the number of patients in whom the specific treatments were commenced or increased. The stacked bars show the five different treatment options. $\mathbb{\mathbb { Q }}$ : commence or increase inhaled steroid; $\square$ : commence or increase prednisone; : commence antibiotics; $\mathbb{Z}$ : no change to current treatment; 曲: other treatment, for example, taking off work in suspected work-related asthma, decreasing the dose of inhaled steroid or adding long-acting $\beta$-agonist).

This was a prospective study in which respirologists in a tertiary care centre participated. It was designed to investigate how often clinical judgment of airway inflammation in patients with asthma was supported by sputum cell counts. If there was considerable disagreement, then further studies to investigate sputum cell counts in the monitoring of asthma would be indicated. The results of the study are perhaps not surprising. Lack of accuracy and reliability in clinical medicine is often encountered [24]. In asthma, there is poor agreement between the assessment of airflow limitation and FEV1 [25], between symptoms and variability of PEF [26], and between clinical assessment and measurement of methacholine airway responsiveness [27]. In the present study, the poor agreement observed between clinical judgment of airway inflammation and objective measurements of sputum cell counts corresponds with these other observations. This and the apparent discrepancy between sputum eosinophilia or lack of it and the degree of airflow limitation (table 2), raises questions about the appropriateness of sputum cell counts as a measure of airway inflammation, and of when and how often the measurements of cell counts in practice will alter the outcomes of treatment.

Sputum cell counts, when performed by reliable methods and trained technologists, as in this study, provide precise information on the presence and type of airway inflammation [11]. There is therefore little doubt that eosinophilic or neutrophilic inflammation was present in 19 and eight patients, respectively, and that this was misinterpreted clinically in $\sim 30 \%$ of patients. This disagreement has been observed in corticosteroid dose-response studies in which maximum clinical improvement can occur before there is a reversal of sputum eosinophilia [28, 29]. However, there may be some doubt about the interpretation of normal sputum cell counts when the physician thought airway inflammation was present. This occurred in $\sim 38 \%$ of the patients. This disagreement could be because the sputum is an insensitive measure of airway inflammation. However, this is unlikely for two reasons. The first is that sputum eosinophils is a sensitive indicator of airway inflammation which develops before clinical exacerbations of asthma [4]. The second is that from the two studies so far comparing sputum with biopsies, when sputum cell counts are normal, usually no eosinophils were found in the biopsies $[16,17]$. The evidence therefore suggests that in the assessment of the presence and type of airway inflammation, objective measurement by sputum cell counts is more accurate than indirect clinical assessment. This does not imply that sputum cell counts are superior to clinical judgement in the assessment of asthma severity or asthma control.

The authors recognize other potential criticisms of the study. Values of $3 \%$ and $80 \%$ were chosen to define significant eosinophilia and neutrophilia, although the authors have recently reported normal values (90th centile) of $1 \%$ and $65 \%$, respectively, for eosinophil and neutrophil differential cell counts [30]. The value of $3 \%$ was chosen to define eosinophilia because previous studies have shown the clinical utility of this value to predict a response to corticosteroid therapy in asthma and chronic airflow limitation $[31,32]$. Since the significance of mild neutrophilia in asthmatics is not well known and particularly since the authors had included some current and exsmokers, it was decided to use a cut-off value of $80 \%$. This has been observed to be associated with mucopurulent and purulent sputum [23], giving the clinicians a fairer chance at guessing the cell count in sputum. Indeed, if the authors were to employ cut-off values of $1 \%$ and $65 \%$ for eosinophilia and neutrophilia, respectively, agreement was less frequent $(24 / 67,36 \%)(\kappa=0.11)$, particularly in the assessment of neutrophilia $(\mathrm{n}=18)$ and combined neutrophilia and eosinophilia $(n=5)$. The over-all result is not different if the eight current smokers were excluded from the analysis.

The relevance of the accurate clinical recognition of airway inflammation relates to the treatment prescribed. There is good evidence that sputum eosinophilia is associated with inflammatory and clinical improvement with corticosteroid treatment [4]. There is increasing evidence that corticosteroid treatment is not effective in the absence of sputum eosinophilia [31-33]. However, it has also been recognized that controlled asthma on inhaled steroids might be associated with persistent sputum eosinophilia [28]. From available evidence, it might appear that 14 patients with a normal sputum cell count and four patients with a significantly high neutrophil count without eosinophilia may not have benefited from an increase in the dose of inhaled corticosteroid or prednisone, whereas 11 of the 19 patients with a raised eosinophil count might have. Since this study was not designed to be a prospective investigation of the outcome of asthma therapy based on sputum cell counts, the authors do not have that information. The results of this study indicate that further investigation is required of when and how often examination of sputum cell counts will alter the outcomes of treatment.

It is concluded that if a person wants to know about the presence and type of airway inflammation, it has to be measured objectively. The impact of such measurements on asthma management strategies and the clinical course of disease have to be evaluated prospectively in future studies. 
Acknowledgements. The authors thank the patients who volunteered to help with this study, the physicians who referred them (G. Berlyne, G. Cox, R. Leigh, E.H. Ramsdale, M.R. Sears), C. Goldsmith for statistical advice, S. Carruthers-Elliott and $\mathrm{S}$. Weston for performing the sputum cell counts.

\section{References}

1. Ernst P, FitzGerald JM, Spier S. Canadian Asthma Consensus Conference: summary of recommendations. Can Respir J 1996; 3: 89-100.

2. The British Thoracic Society. The British Guidelines on asthma management 1995 review and position statement. Thorax 1997; 52 (Suppl. 1): S1-S21.

3. Bousquet J, Chanez P, Lacoste JY, et al. Eosinophilic inflammation in asthma. $N$ Engl J Med 1990; 323: 10331039.

4. Pizzichini MMM, Pizzichini E, Clelland L, et al. Sputum in severe exacerbations of asthma: kinetics of inflammatory indices after prednisone treatment. Am J Respir Crit Care Med 1997; 155: 1501-1508.

5. Claman DM, Boushey HA, Liu J, Wong H, Fahy JIV. Analysis of induced sputum to examine the effect of prednisone on airway inflammation in asthmatic subjects. J Allergy Clin Immunol 1994; 94: 861-869.

6. Kendrick AH, Higgs CMB, Whitfield MJ, Laszlo G. Accuracy of perception of severity of asthma: patients treated in general practice. BMJ 1993; 307: 422-424.

7. Haley KJ, Drazen JM. Inflammation and airway function in asthma: what you see is not necessarily what you get. Am J Respir Crit Care Med 1998; 157: 1-3.

8. Parameswaran K, Pizzichini MMM, Li D, Pizzichini E, Jeffery PK, Hargreave FE. Serial sputum cell counts in chronic airflow limitation. Eur Respir J 1998; 11: 14051408 .

9. Pizzichini MMM, Pizzichini E, Efthimiadis A, et al. Asthma and natural colds: inflammatory indices in induced sputum. A feasibility study. Am J Respir Crit Care Med 1998; 158: 1178-1184.

10. Fahy JV, Wong HH, Liu JT, Boushey HA. Analysis of induced sputum after air and ozone exposures in healthy subjects. Environ Res 1995; 70: 77-83.

11. Pizzichini E, Pizzichini MMM, Efthimiadis A, et al. Indices of airway inflammation in induced sputum: reproducibility and validity of cell and fluid phase measurements. Am J Respir Crit Care Med 1996; 154: 308-317.

12. Fahy JV, Liu J, Wong H, Boushey HA. Cellular and biochemical analysis of induced sputum from asthmatic and from healthy subjects. Am Rev Respir Dis 1993; 147: 1126-1131.

13. Ronchi MC, Piragino C, Rosi E, Amendola M, Duranti R, Scano G. Role of sputum differential count in detecting airway inflammation in patients with chronic bronchial asthma or COPD. Thorax 1996; 51: 1000-1004.

14. Fahy JV, Wong H, Liu J, Boushey HA. Comparison of samples collected by sputum induction and bronchoscopy from asthmatic and healthy subjects. Am J Respir Crit Care Med 1995; 152: 53-58

15. Keatings VM, Evans DJ, O'Connor BJ, Barnes PJ. Cellular profiles in asthmatic airways: a comparison of induced sputum, bronchial washings and bronchoalveolar lavage fluid. Thorax 1997; 52: 372-374.

16. Maestrelli P, Saetta M, Stefano AD, et al. Comparison of leukocyte counts in sputum, bronchial biopsies and bronchoalveolar lavage. Am J Respir Crit Care Med 1995; 152: 1926-1931.

17. Grootendorst DC, Sont JK, Willems LNA, et al. Comparison of inflammatory cell counts in asthma: induced sputum versus bronchoalveolar lavage and bronchial biopsies. Clin Exp Allergy 1997; 27: 769-779.

18. Pizzichini E, Pizzichini MMM, Kidney JC, et al. Induced sputum, bronchoalveolar lavage and blood from mild asthmatics: inflammatory cells, lymphocyte subsets and soluble markers compared. Eur Respir J 1998; 11: 828834.

19. Pizzichini MMM, Popov TA, Efthimiadis A, et al. Spontaneous and induced sputum to measure indices of airway inflammation in asthma. Am J Respir Crit Care Med 1996; 154: 866-869.

20. American Thoracic Society. Standardization of spirometry: 1987 update. Am Rev Respir Dis 1987; 136: 12851298.

21. Pepys J. Skin tests in diagnosis. In: Gell PGH, Coombs RRA, Lachmann PJ, eds. Clinical aspects of immunology. 3rd Edn. Oxford, UK, Blackwell Scientific Publications, 1975; pp. 55-80.

22. Pizzichini E, Pizzichini MMM, Efthimiadis A, Hargreave FE, Dolovich J. Measurement of inflammatory indices in induced sputum: effects of selection of the sputum to minimize salivary contamination. Eur Respir J 1996; 9: 1174-1180.

23. Berlyne GS, Efthimiadis A, Hussack P, Groves D, Dolovich J, Hargreave FE. Sputum in asthma: colour versus cell counts. J Allergy Clin Immunol 2000; 104: 182-183.

24. Koran LM. The reliability of clinical methods, data and judgements. N Engl J Med 1975; 293: 642-646.

25. Spiteri MA, Cook DG, Clarke SW. Reliability of eliciting physical signs in examination of the chest. Lancet 1988; i: 873-875.

26. Gibson PG, Wong BJO, Hepperle MJE, et al. A research method to induce and examine a mild exacerbation of asthma by withdrawal of inhaled corticosteroid. Clin Exp Allergy 1992; 22: 525-532.

27. Adelroth E, Hargreave FE, Ramsdale EH. Do physicians need objective measurements to diagnose asthma? Am Rev Respir Dis 1986; 134: 704-707.

28. Fahy JV, Boushey HA. Effect of low-dose beclomethasone dipropionate on asthma control and airway inflammation. Eur Respir J 1998; 11: 1240-1247.

29. Jatakanon A, Kharitonov SA, Lim S, Barnes PJ. Effect of differing doses of inhaled budesonide on markers of airway inflammation in patients with mild asthma. Thorax 1999; 54: 108-114.

30. Belda J, Leigh R, Parameswaran K, O'Byrne PM, Sears MR, Hargreave FE. Induced sputum cell counts in healthy adults. Am J Respir Crit Care Med 2000; In press.

31. Pizzichini E, Pizzichini MMM, Gibson PG, et al. Sputum to predict benefit from prednisone in smokers with chronic obstructive bronchitis. Am J Respir Crit Care Med 1998; 158: 1511-1517.

32. Pavord ID, Brightling CD, Woltmann G, Wardlaw AJ. Non-eosinophilic corticosteroid unresponsive asthma. Lancet 1999; 353: 2213-2214.

33. Pizzichini MMM, Pizzichini E, Parameswaran K, et al. Non-asthmatic chronic cough: no effect of treatment with an inhaled corticosteroid in patients without sputum eosinophilia. Can Respir J 1999; 6: 323-330. 